\title{
Occupational exposure to pesticides are associated with fixed airflow obstruction in middle-age
}

\author{
Sheikh M Alif, ${ }^{1}$ Shyamali C Dharmage, ${ }^{1,2}$ Geza Benke, ${ }^{3}$ Martine Dennekamp, ${ }^{3,4}$ \\ John A Burgess, ${ }^{1}$ Jennifer L Perret, ${ }^{1,5}$ Caroline J Lodge, ${ }^{1}$ Stephen Morrison, ${ }^{6}$ \\ David Peter Johns, ${ }^{7}$ Graham G Giles, ${ }^{1,2,8}$ Lyle C Gurrin, ${ }^{1,2}$ Paul S Thomas, ${ }^{9}$ \\ John Llewelyn Hopper, ${ }^{1}$ Richard Wood-Baker, ${ }^{7}$ Bruce R Thompson, ${ }^{10}$ lain H Feather, ${ }^{11,12}$ \\ Roel Vermeulen, ${ }^{13}$ Hans Kromhout, ${ }^{13}$ E Haydn Walters, ${ }^{1,3,7}$ Michael J Abramson, ${ }^{3}$ \\ Melanie Claire Matheson ${ }^{1,2}$
}

\begin{abstract}
- Additional material is published online only. To view please visit the journal online (http://dx.doi.org/10.1136/ thoraxjnl-2016-209665)
\end{abstract}

For numbered affiliations see end of article.

\section{Correspondence to}

Professor Shyamali C Dharmage, Head of the Allergy and Lung Health Unit, Centre for Epidemiology and Biostatistics, School of Population and Global Health, Faculty of Medicine, Dentistry and Health Sciences, The University of Melbourne, Level 3, 207 Bouverie St, Carlton 3010; s.dharmage@ unimelb.edu.au

Received 2 November 2016 Revised 24 April 2017

Accepted 1 May 2017 Published Online First 20 June 2017

CrossMark

To cite: Alif SM

Dharmage SC, Benke G, et al.

Thorax 2017:72:990-997.
ABSTRACT
Rationale Population-based studies have found

evidence of a relationship between occupational exposures and Chronic Obstructive Pulmonary Disease (COPD), but these studies are limited by the use of prebronchodilator spirometry. Establishing this link using postbronchodilator is critical, because occupational exposures are a modifiable risk factor for COPD.

Objectives To investigate the associations between occupational exposures and fixed airflow obstruction using postbronchodilator spirometry.

Methods One thousand three hundred and thirty-five participants were included from 2002 to 2008 followup of the Tasmanian Longitudinal Health Study (TAHS). Spirometry was performed and lifetime work history calendars were used to collect occupational history. ALOHA plus Job Exposure Matrix was used to assign occupational exposure, and defined as ever exposed and cumulative exposure unit (EU)-years. Fixed airflow obstruction was defined by postbronchodilator FEV,/FVC $<0.7$ and the lower limit of normal (LLN). Multinomial logistic regressions were used to investigate potential associations while controlling for possible confounders. Results Ever exposure to biological dust (relative risk $(R R)=1.58,95 \% \mathrm{Cl} 1.01$ to 2.48$)$, pesticides ( $R R=1.74,95 \% \mathrm{Cl} 1.00$ to 3.07 ) and herbicides ( $R R=2.09,95 \% \mathrm{Cl} 1.18$ to 3.70 ) were associated with fixed airflow obstruction. Cumulative EU-years to all pesticides ( $R R=1.11,95 \% \mathrm{Cl} 1.00$ to 1.25$)$ and herbicides ( $R R=1.15,95 \% \mathrm{Cl} 1.00$ to 1.32 ) were also associated with fixed airflow obstruction. In addition, all pesticides exposure was consistently associated with chronic bronchitis and symptoms that are consistent with airflow obstruction. Ever exposure to mineral dust, gases/fumes and vapours, gases, dust or fumes were only associated with fixed airflow obstruction in non-asthmatics only. Conclusions Pesticides and herbicides exposures were associated with fixed airflow obstruction and chronic bronchitis. Biological dust exposure was also associated with fixed airflow obstruction in non-asthmatics. Minimising occupational exposure to these agents may help to reduce the burden of COPD.

\section{INTRODUCTION}

Chronic Obstructive Pulmonary Disease (COPD) characterised by postbronchodilator (BD) fixed

\section{Key messages}

What is the key question?

- What are the associations between occupational exposure and fixed airflow obstruction?

What is the bottom line?

- This study has shown that pesticides and herbicides exposures were associated with fixed airflow obstruction, chronic bronchitis and respiratory symptoms.

Why read on?

- This study is the first to describe an association between all pesticides exposure and fixed airflow obstruction, and certain exposures were only associated with fixed airflow obstruction in non-asthmatics but not in asthmatics.

airflow obstruction (AO) is a chronic debilitating respiratory condition and a growing cause of mortality and morbidity worldwide. ${ }^{1}$ Tobacco smoking remains the predominant risk factor for COPD. ${ }^{2}$ However, it is now well established that non-smokers also develop COPD and the interest in non-smoking-related risk factors for COPD have exponentially increased in the recent past. ${ }^{3}$ Occupational exposures are an important potentially modifiable risk factor for COPD, and while the population-based studies conducted to date have provided valuable information about the importance of these exposures in COPD they have had some important limitations.

We recently performed a systematic review assessing the association between occupational exposure to dusts, gases and fumes, and COPD in population-based studies that used job exposure matrices. ${ }^{4}$ Our review found an overall association between occupational exposures to mineral dust and gases/fumes and COPD. However, the results varied by definitions of COPD and only one study to date had used post-BD spirometry to define COPD. ${ }^{5}$ This is an important limitation in the current literature as the post-BD measurement of $\mathrm{AO}$ is the gold standard to define fixed $\mathrm{AO},{ }^{6}$ which is the hallmark feature of COPD. ${ }^{1}$ The one study that did use post-BD to define $\mathrm{AO}$ did not find any 
association between dust, gases/fumes and fixed $\mathrm{AO} .{ }^{5}$ However, the age range of this cohort was very broad and more than a quarter of the cohort were younger than 45 years. This highlights a further limitation of the existing studies in this area; they are relatively young cohorts who are not likely to have developed significant fixed AO. Furthermore, only few population-based studies have investigated the effects of lifetime occupational exposures assessed over an individual's complete working life, ${ }^{578}$ which allows for assessment of cumulative exposure. ${ }^{9}$ Our systematic review concluded that the combination of young cohorts with pre-BD lung function and the lack of assessment of lifetime occupational exposures highlight the need for further studies in this area addressing these issues.

Another limitation of the existing literature around occupational exposures and COPD is the lack of studies examining pesticide exposures. There is increasing evidence that pesticide exposure is associated with respiratory symptoms and diseases, with the strongest evidence for asthma. ${ }^{10} 11$ Recent studies from the Netherlands have found an association between pesticide and COPD,${ }^{12}$ and lung function decline. ${ }^{13}$ However, these studies are again limited by the use of pre-BD spirometry, which does not allow for the identification of fixed AO.

Given the limitations in the studies conducted to date, we investigated the association between occupational exposure and COPD using post-BD spirometry in a general population. We explored both ever exposure and cumulative exposure unit (EU)-years of occupational exposure. Some of the results of this study have been previously published in the form of an abstract. ${ }^{14}$

\section{METHODS}

\section{Study design and participants}

We included participants from the 2002 to 2008 follow-up of the population-based Tasmanian Longitudinal Health Study (TAHS), details of which have been reported elsewhere, ${ }^{15}$ and are summarised in figure 1. Briefly, TAHS started in 1968 when all children aged 7 years $(n=8583)$ attending school in Tasmania were enrolled in a study of asthma. Their parents completed a respiratory health questionnaire, and the children underwent a clinical examination and lung function measurements. Follow-up surveys were conducted in 1974, 1979 and 1991 at the ages of 12, 18 and 30 years, respectively. The 2002-2008 follow-up started in 2002 when participants were in their fifth decade of life. We traced 7562 (88.1\%) of the original 1968 cohort to a residential address and achieved a response of 5729 (78.4\%) to a postal survey. A subgroup of these respondents, selected from their participation in previous follow-ups and enriched for participants with a history of asthma and bronchitis, were invited to participate in a more detailed laboratory study and information was collected using questionnaire, pre-BD and post-BD lung function test, skin prick testing, lung volumes and diffusing capacity. Of 2387 invited, 1397 (58.6\%) took part in full laboratory testing, 354 (14.8\%) completed a telephone questionnaire only and 636 (26.7\%) withdrew from the study. The 2002 to 2008 follow-up was approved

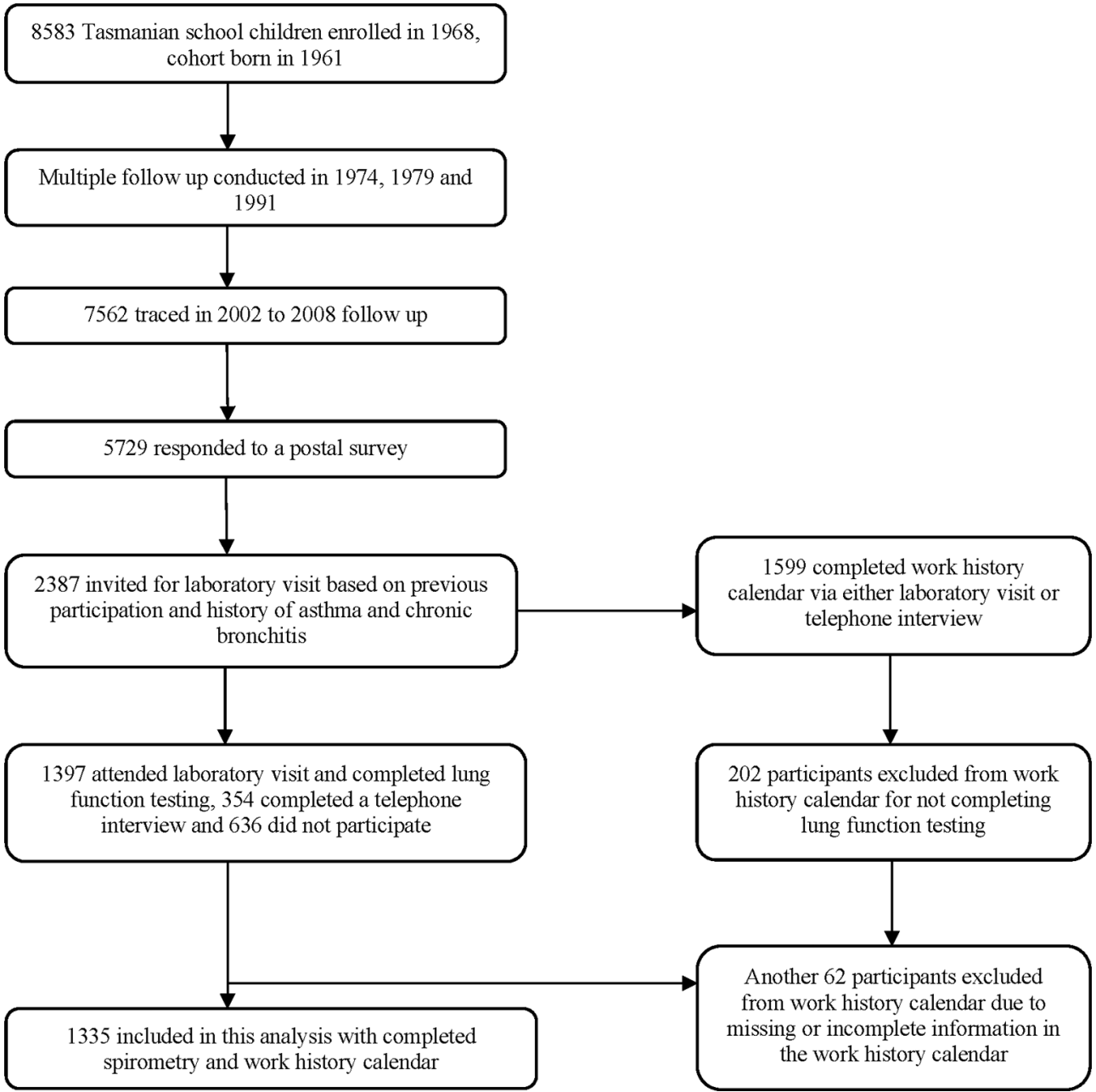

Figure 1 Tasmanian Longitudinal Health Study flow diagram. 
by the Human Research Ethics Committee of the University of Melbourne (HREC no. 040375). All participants provided written informed consent.

\section{Data collection}

Pre-BD and post-BD lung function was measured with the Easyone Ultrasonic spirometer (ndd, Medizintechnik, AG, Switzerland). Participants were asked not to smoke for 4-6hours before testing. $\mathrm{FEV}_{1}$ and $\mathrm{FVC}$ were measured according to international guidelines and the highest value for $\mathrm{FEV}_{1}$ and FVC obtained from three acceptable and repeatable tests was recorded. ${ }^{16}$ Spirometry was repeated $10-15 \mathrm{~min}$ after short-acting bronchodilator $(200 \mu \mathrm{g}$ salbutamol) administration via a spacer.

\section{Outcome definitions}

Fixed AO was defined according to Global Initiative for Chronic Obstructive Lung Disease (GOLD) criteria: ratio of post-BD $\mathrm{FEV}_{1}$ and $\mathrm{FVC}\left(\mathrm{FEV}_{1} / \mathrm{FVC}\right)<0.70 .{ }^{17}$ We also used the lower limit of normal (LLN) to define fixed AO, on the basis of Global Lung Function Initiative 2012 regression equations. ${ }^{18}$

- Chronic bronchitis was defined as a cough with phlegm on most days for at least 3 months of each year for 2 successive years. $^{17}$

- Chronic cough was defined as usually cough without a cold on most days for at least 3 months for at least 2 years.

- Chronic phlegm was defined as usually phlegm without a cold on most days for at least 3 months for at least 2 years.

- Dyspnoea was defined as shortness of breath when hurrying on level ground or walking up a slight hill.

\section{Occupational exposures}

Occupational exposures were classified using the lifetime work history calendar that was collected from participants during the laboratory visit or telephone interview. A total of 1599 participants provided complete work histories, but this analysis was restricted to 1335 participants who completed both spirometry testing at the 2002 to 2008 follow-up and the work history calendar. Participants were asked to list all the jobs they had held in their lifetime including job title, industry name, employer name, year work started and ended. The job titles reported by the participants were coded according to the International Standard Classification of Occupations- 88 four-digit classification. ${ }^{19}$ These codes were then used to establish occupational exposures to biological dust, mineral dust, gases/fumes, vapours, gases, dust or fumes (VGDF), all pesticides, herbicides and insecticides using a modified version of the ALOHA Job Exposure Matrix called the ALOHA plus Job Exposure Matrix. $^{12}$ The ALOHA plus Job Exposure Matrix classified participants based on job codes into no, low, or high exposure categories. For this analysis, we combined low and high exposure categories because of a small number of participants in the low exposed group limited the statistical analysis. Ever exposure was calculated by summing exposures over all jobs for each participant. In case of participants having two different jobs at the same time, exposures from both jobs were averaged and rounded up to the nearest integer $(0.5=1$ and $1.5=2){ }^{12}$

The ALOHA plus Job Exposure Matrix was also used to calculate cumulative EU- years by multiplying the number of years worked multiplied by the exposure intensity (ie, low or high exposure) for each job and then summed for each participant over the entire job history. To allow for the combination of low and high exposure groups, years of exposure were weighted by four for high exposure and one for low exposure. ${ }^{57}$ This cumulative EU-years was calculated for each of the exposure types and scaled continuous variable of cumulative exposure per 10 years. Participants missing any years in the lifetime work history calendar were excluded from the cumulative EU-years analysis and so 1255 participants were included in the unadjusted analysis.

\section{Statistical analysis}

All the statistical analyses were conducted using Stata V.13.1 (StataCorp, College Station, Texas, USA). The population prevalence of the outcomes were estimated as observed proportions with 95\% CI based on the binomial distribution. The estimate prevalences was calculated using inverse-probability-of-inclusion weights to adjust for the enriched sample of the 2002 to 2008 follow-up. The associations between outcomes and occupational exposures were estimated using multinomial logistic regression models. We adjusted for sex, smoking, pack-years, asthma in childhood and adulthood, and socioeconomic status in childhood and adulthood. Due to the correlation between any VGDF exposure and all pesticides exposure (see online supplementary table 6) all models that examined biological dust, mineral dust, gases/fumes or VGDF exposures were additionally adjusted for ever exposure to all pesticides. Similarly, models examining all pesticides, herbicides or insecticides exposure were additionally adjusted for VGDF exposure.

Effect modification by sex, smoking and current asthma was assessed by including interaction terms (occupational exposure $\times$ sex, occupational exposure $\times$ smoking, occupational exposure $\times$ current asthma) in the models. We performed a multiple imputation analysis to impute the values of missing confounders and compared this analysis with the complete-case analysis. The results of the imputed analysis did not differ from the completecase analysis and the results of the imputation analysis are presented in online supplementary tables 3, 4 and 5). A p value $\leq 0.05$ was considered to be statistically significant.

\section{RESULTS}

\section{Characteristics of study population}

A comparison of responders and non-responders to the laboratory study and postal survey for selected characteristics can be found in the online supplementary table 1 . Briefly selected characteristics of the participants those who did and did not attend the laboratory study were similar. Table 1 shows the characteristics of included study participants. The mean age of the participants was 44.8 years $( \pm 0.8 \mathrm{SD})$, over half $(51.6 \%)$ were men, $87.4 \%$ were currently employed and $25.1 \%$ were current smokers, with a median smoking history of 21 pack-years (Table 1). There was very little difference in the prevalence of fixed $\mathrm{AO}$ when using the GOLD $(6 \% ; 95 \%$ CI 4.8 to 7.6$)$ or LLN $(6 \% ; 95 \%$ CI 4.8 to 7.5$)$ criteria. The prevalence of chronic bronchitis was $8.6 \%(95 \% \mathrm{CI}$ 7.6 to 9.9 ) and dyspnoea $12.1 \%$ (95\% CI 10.4 to 14.1$)$. Over $28 \%$ of all participants had ever reported asthma.

\section{Ever exposure}

Table 2 shows the association between ever exposure and fixed $\mathrm{AO}$, chronic bronchitis and respiratory symptoms. Ever exposed to biological dust was associated with fixed $\mathrm{AO}$ (relative risk $(\mathrm{RR})=1.58,95 \%$ CI 1.01 to 2.48 ), while mineral dust was associated with symptoms. Ever exposed to gases/fumes was not associated with fixed $\mathrm{AO}$ or symptoms.

Ever exposure to all pesticides was associated with GOLD-defined fixed $\mathrm{AO}$, chronic bronchitis and also with all respiratory symptoms (table 2). Ever exposed to herbicides was also associated with fixed AO, chronic bronchitis and chronic cough. Ever 


\begin{tabular}{|c|c|c|}
\hline Study characteristics & $\mathrm{n}(\%)^{*}$ & $95 \% \mathrm{Cl}$ \\
\hline Age, years (mean, SD) $(n=1334)$ & $44.8(0.8)$ & 44.7 to 44.9 \\
\hline \multicolumn{3}{|l|}{ Sex, \% $(n=1335)$} \\
\hline Men & $684(51.6)$ & 48.5 to 54.9 \\
\hline Women & $651(48.3)$ & 45.0 to 51.5 \\
\hline \multicolumn{3}{|l|}{ Smoking history $(n=1330)$} \\
\hline Never, $\mathrm{n}(\%)$ & $566(45.3)$ & 42.1 to 48.6 \\
\hline $\begin{array}{l}\text { Past, } n(\%) \\
\text { Pack-years, median (IQR) }(n=1292)\end{array}$ & $\begin{array}{l}394(29.6) \\
7.5(2-17)\end{array}$ & 26.7 to 32.6 \\
\hline $\begin{array}{l}\text { Current, } n(\%) \\
\text { Pack-years, median (IQR) ( } n=1292)\end{array}$ & $\begin{array}{l}370(25.1) \\
21(10-30)\end{array}$ & 22.4 to 27.9 \\
\hline Currently employed, $n(\%)(n=1332)$ & $1136(87.4)$ & 85.2 to 89.3 \\
\hline \multicolumn{3}{|l|}{ Fixed airflow obstruction (AO) } \\
\hline Fixed AO-GOLD (n=1335) & $113(6.0)$ & 4.8 to 7.6 \\
\hline $\begin{array}{l}\text { Stage I: } \mathrm{FEV}_{1} / \mathrm{FVC}<0.7 \text { and } \\
\mathrm{FEV}_{1} \geq 80 \%\end{array}$ & $62(3.7)$ & 2.7 to 5.1 \\
\hline $\begin{array}{l}\text { Stage II: } \mathrm{FEV}_{1} / \mathrm{FVC}<0.7 \text { and } \\
\mathrm{FEV}_{1}<80 \%\end{array}$ & $51(2.3)$ & 1.7 to 3.2 \\
\hline Fixed A0-LLN ( $n=1335)$ & $112(6.0)$ & 4.8 to 7.5 \\
\hline Chronic bronchitis $(n=1322)$ & $246(8.7)$ & 7.6 to 9.9 \\
\hline \multicolumn{3}{|l|}{ Respiratory symptoms } \\
\hline Chronic cough ( $n=1316$ ) & $185(8.8)$ & 7.4 to 10.3 \\
\hline Chronic phlegm $(n=1317)$ & $171(6.8)$ & 5.8 to 8.1 \\
\hline Dyspnoea $(n=1334)$ & $227(12.1)$ & 10.4 to 14.1 \\
\hline
\end{tabular}

${ }^{*}$ The estimated prevalences were calculated using inverse-probability-of-inclusion weights to adjust for the enriched sample of the fifth decade follow-up survey. AO, airflow obstruction; GOLD, Global Obstructive Lung Disease; LLN, lower limit of normal.

exposed to insecticides was associated with chronic bronchitis and chronic cough. Using LLN definition of fixed AO (table 2), we found a significant association between ever exposure to herbicides and fixed $\mathrm{AO}$ and a trend of association between all pesticides and insecticides and fixed AO. In general, using both definitions, we found both all pesticides and herbicides were associated with fixed $\mathrm{AO}$.

\section{Cumulative EU-years}

For every 10-year increase in cumulative EU-years of exposure to biological dust, there was a $7 \%$ increase of chronic cough $(\mathrm{RR}=1.07,95 \% \mathrm{CI} 1.00$ to 1.15$)$. Cumulative EU-years of exposure to mineral dust and gases and fumes were associated with a $5 \%$ increase of dyspnoea (table 3). Cumulative EU-years of exposure to all pesticides was consistently associated with both definitions of fixed $\mathrm{AO}$, chronic bronchitis, chronic cough and chronic phlegm. Cumulative EU-years of exposure to herbicides was associated with fixed $\mathrm{AO}$ and chronic bronchitis. Cumulative EU-years of exposure to insecticides was associated with $15 \%$ increase of chronic bronchitis ( $\mathrm{RR}=1.15,95 \% \mathrm{CI} 1.02$ to 1.29$)$.

\section{Interactions with sex, smoking and current asthma}

We explored the potential interactions between occupational exposures and sex, smoking and current asthma. We did not find any interactions with sex or smoking (data not shown). However, we found significant interactions between ever exposure and current asthma. We found a significant interaction between current asthma and biological dust (interaction $\mathrm{p}=0.003$ ), mineral dust (interaction $\mathrm{p}=0.03$ ), gases/fumes (interaction $p=0.005)$ and VGDF (interaction $p=0.01$ ) for GOLD-defined fixed AO (table 4). For all of these occupational exposures, there was association with fixed $\mathrm{AO}$ in the non-asthmatic group but not in the asthmatic group.

\section{DISCUSSION}

This is the first study to examine fixed AO using the gold standard measurement of post-BD spirometry and two measures of occupational exposure, ever exposure and lifetime cumulative EU-years. Using these robust measures, we have demonstrated significant and consistent associations between all pesticides exposure, fixed $\mathrm{AO}$, chronic bronchitis and chronic cough. We are the first to show that ever exposure to pesticides is associated with fixed $\mathrm{AO}$ and increasing cumulative EU-years to pesticides are associated with fixed $\mathrm{AO}$.

A number of previous workplace-based studies have reported increased prevalence of respiratory symptoms and reduced lung function among farmers or agriculture workers exposed to pesticides. ${ }^{20-23}$ However, there has only been one population-based study published in relation to pesticides exposure and AO. This study examined two Dutch cohorts and found an association between pre-BD AO in people exposed to pesticides in one cohort, and a trend towards an association in the other for moderate/severe $\mathrm{AO}$ (defined as pre-BD $\mathrm{FEV}_{1} / \mathrm{FVC}<70 \%$ and $\left.\mathrm{FEV}_{1}<80 \%\right) .{ }^{12}$ Both cohorts in this study used pre-BD spirometry to define $\mathrm{AO}$, which may have overestimated the prevalence of AO. They also used current or last held job and the results may have been confounded by past exposure. We have demonstrated, in a similarly aged population, an association between ever exposure and cumulative EU-years to all pesticides and fixed AO confirming that minimising exposure to all pesticides may help to reduce the burden of COPD.

We also observed significant association between chronic bronchitis, chronic cough and chronic phlegm with both ever exposure and cumulative EU-years to pesticides. We are first to show cumulative EU-years to pesticides is associated with chronic respiratory symptoms in a population-based study. Recent systematic reviews found chronic bronchitis was associated with pesticides exposure ${ }^{1024}$ and a study of the US farmers found association between exposure to pesticides and chronic bronchitis. ${ }^{20}$ Similar to our findings, a study from Latin America also found an association between pesticides exposure and respiratory symptoms. ${ }^{21}$ However, all these studies were conducted in specific occupational groups making the results not applicable to the broader general population, unlike the results from our study.

Pesticides can be classified according to their targets into three main areas: insecticides, herbicides and fungicides. Insecticides include organochlorines, organophosphates and carbamates. Herbicides include phenoxy herbicides and fungicides include dithiocarbamates, and all have been used extensively in agriculture to control pests and weeds. ${ }^{10}$ Pesticides can enter the body through inhalation into the respiratory tract and absorption through the skin during use for fumigation, preparation and spraying or during manufacture, storage or transport. ${ }^{10} 24$ Long-term exposure to organophosphate and carbamate pesticides has been shown to lead to inhibition of acetylcholinesterase synthesis from M2 muscarinic receptors that results in mucus hypersecretion and airway smooth muscle contraction causing breathlessness, cough and wheeze. ${ }^{1024}$ The inactive acetylcholinesterase is also responsible for thickening of alveolar-capillary membrane leading to reduced level of lung function. ${ }^{25}$

The ALOHA plus Job Exposure Matrix assigned exposure to pesticides as ever exposure to all pesticides and then also had 


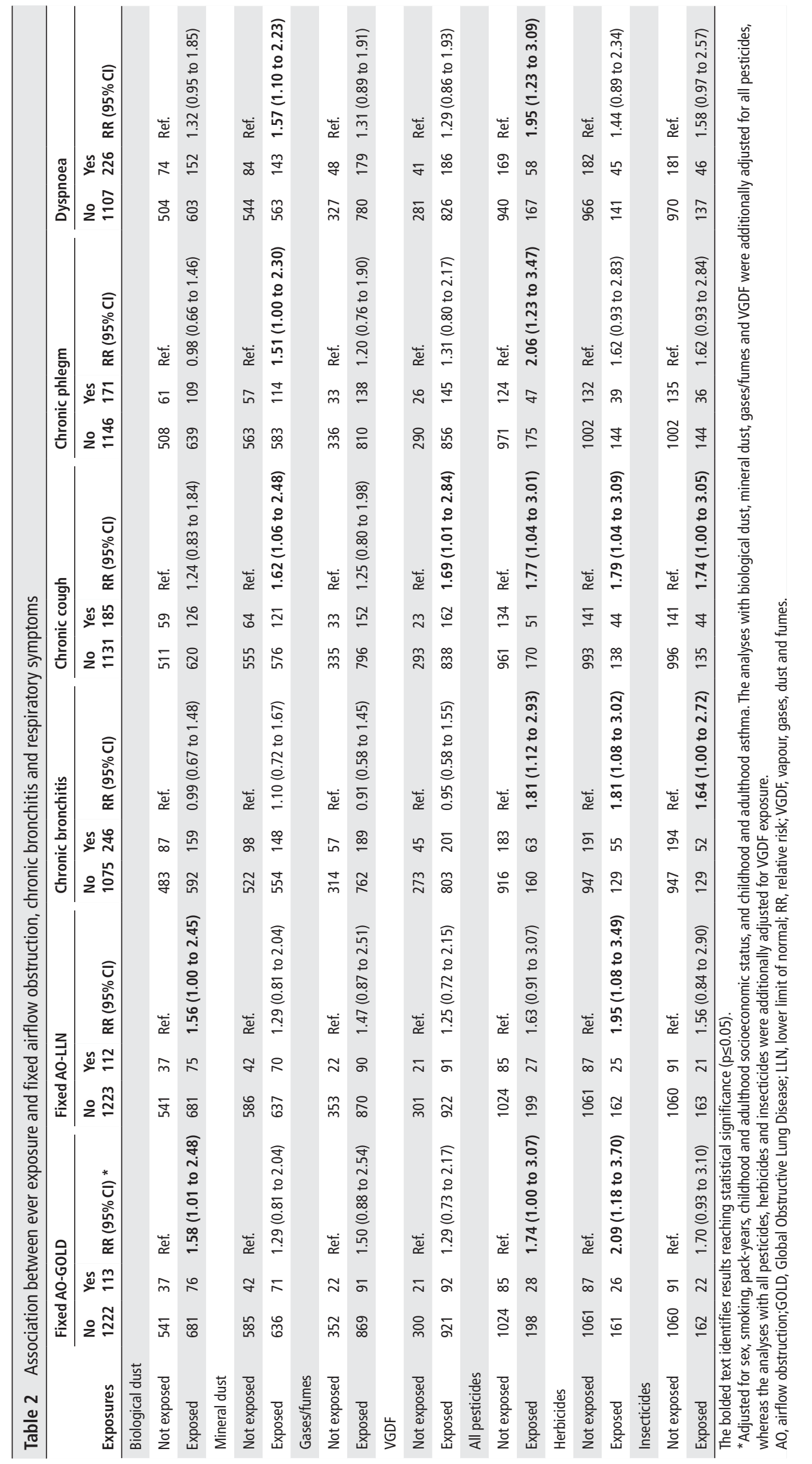




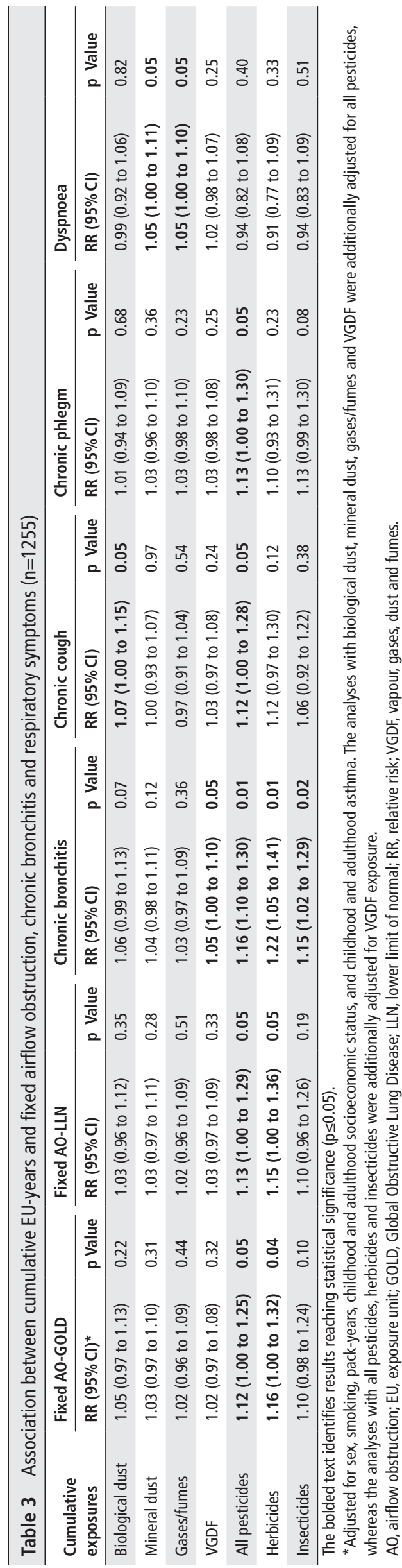

subcategories of specific herbicides and insecticides exposures. The associations observed in this study were largely consistent across all three categories, with some not quite reaching statistical significance for some symptoms. The possible explanation for this slight variation across the subcategories of all pesticides exposure is differences in exposures between different occupational groups with some groups, for example, cattle farmers not being exposed to herbicides but to insecticides. Another example of this is forestry workers who formed a large proportion of our exposed workers (23.8\%), but who had 'all pesticides exposure' and 'herbicides exposure' but not 'insecticides exposure'. Another explanation is the presence of very strong correlation between these exposures (see online supplementary table 6). In our study, participants with high all pesticides exposures included people who described themselves as farm hands/ labourers, forestry workers, gardeners, horticultural/nursery workers, and crop/vegetable growers.

For the other common exposures to biological dust, mineral dust and gases/fumes, we only observed association with fixed $\mathrm{AO}$ for those ever exposed to biological dust. This finding is consistent with previous studies that have also found association between biological dust and COPD. ${ }^{719}$ The finding with biological dust in the present study is also consistent with the meta-analysis conducted by our group, although the effect estimates did not reach statistical significance in our meta-analysis. ${ }^{4}$ The reason for this slight variation in the effect estimate may be due to the inclusion of pre-BD in most of the included studies in our meta-analysis. We did not observe any association between mineral dust and gases/fumes exposure and fixed AO, but we did observe associations with respiratory symptoms. Several previous studies also found an association between dust exposure in general and respiratory symptoms. ${ }^{26} 27$

Our study observed a significant interaction between current asthma and four of the occupational exposures for fixed AO. In the non-asthmatics, there was an association between ever exposure to biological dust, mineral dust and gases/fumes and fixed AO, even with a low crude prevalence of $7.12 \%$ in non-asthmatics, compared with asthmatics (16.98\%). We did not observe the same interaction for cumulative EU-years to these agents. This finding is suggestive of a healthy worker effect, that is, asthmatics who remain in the study are relatively unaffected by these occupational exposures. It also may suggest that asthma alone is a significant risk factor for fixed $\mathrm{AO}$ in middle-age and additional occupational exposure does not substantially increase the risk observed at this age. We did explore childhood asthma status, recorded prospectively in this cohort, but we did not find any interaction with occupational exposures and fixed $\mathrm{AO}$. We also did not observe any interaction between current asthma and all pesticides for fixed $\mathrm{AO}$ suggesting the ever exposure and cumulative EU-years of all pesticides significantly associated with fixed $\mathrm{AO}$ independent of asthma.

Previous studies of occupational exposure and COPD using the ALOHA Job Exposure Matrix have taken asthma into account in their analysis by different methods. They have either excluded asthmatics completely ${ }^{81928}$ or performed sensitivity analysis to see if excluding participants with asthma influenced the results. ${ }^{57}$ Including participants with asthma would inflate the prevalence of fixed $\mathrm{AO}$, especially if pre-BD was used in a relatively young cohort, as was the case for several of these studies, ${ }^{128}$ leading to spurious results. We included both childhood and adult asthma as a confounder in the statistical analyses and investigated the possible interaction with current asthma. Our study has demonstrated for the first time in a general population that asthma significantly modifies the effect of biological dust, mineral dust and gases, and fumes on fixed $\mathrm{AO}$ in middle-age. 
Table 4 Association between ever exposure to biological dust, mineral dust, gases/fumes and VGDF stratified by current asthma

\begin{tabular}{|c|c|c|c|c|c|c|c|}
\hline \multirow[b]{3}{*}{ Exposures } & \multicolumn{3}{|c|}{ Current asthmatics } & \multicolumn{3}{|c|}{ Non-asthmatics } & \multirow[b]{3}{*}{$\begin{array}{l}\text { Interactior } \\
\text { p Value* }\end{array}$} \\
\hline & \multicolumn{3}{|c|}{ Fixed AO-GOLD } & \multicolumn{3}{|c|}{ Fixed AO-GOLD } & \\
\hline & $\begin{array}{l}\text { No } \\
\%(n / N)\end{array}$ & $\begin{array}{l}\text { Yes } \\
\%(n / N)\end{array}$ & RR $(95 \% \mathrm{Cl})$ & $\begin{array}{l}\text { No } \\
\%(n / N)\end{array}$ & Yes $\%(n / N)$ & $\operatorname{RR}(95 \% \mathrm{Cl})$ & \\
\hline Biological dust & $\begin{array}{l}63 \% \\
(167 / 265)\end{array}$ & $\begin{array}{l}55.6 \% \\
(25 / 45)\end{array}$ & 0.68 (0.35 to 1.34 ) & $\begin{array}{l}53.6 \% \\
(512 / 955)\end{array}$ & $\begin{array}{l}75 \% \\
(51 / 68)\end{array}$ & 2.80 (1.48 to 5.27$)$ & 0.003 \\
\hline Mineral dust & $\begin{array}{l}56 . \% \\
(149 / 266)\end{array}$ & $\begin{array}{l}53.3 \% \\
(24 / 45)\end{array}$ & 0.70 (0.35 to 1.38 ) & $\begin{array}{l}50.9 \% \\
(486 / 955)\end{array}$ & $\begin{array}{l}69.1 \% \\
(47 / 68)\end{array}$ & 1.80 (0.98 to 3.32 ) & 0.03 \\
\hline Gases/fumes & $\begin{array}{l}76.3 \% \\
(203 / 266)\end{array}$ & $\begin{array}{l}71.1 \% \\
(32 / 45)\end{array}$ & 0.61 (0.29 to 1.29 ) & $\begin{array}{l}69.6 \% \\
(665 / 955)\end{array}$ & $\begin{array}{l}86.8 \% \\
(59 / 68)\end{array}$ & 2.92 (1.27 to 6.67$)$ & 0.005 \\
\hline VGDF & $\begin{array}{l}79.7 \% \\
(212 / 266)\end{array}$ & $\begin{array}{l}73.3 \% \\
(33 / 45)\end{array}$ & 0.57 (0.26 to 1.22$)$ & $\begin{array}{l}74.1 \% \\
(708 / 955)\end{array}$ & $\begin{array}{l}86.8 \% \\
(59 / 68)\end{array}$ & $2.33(1.01$ to 5.34$)$ & 0.01 \\
\hline
\end{tabular}

The bolded text identifies results reaching statistical significance $(p \leq 0.05)$.

${ }^{*} p \leq 0.05$ for the interaction between exposure and current asthma.

†Adjusted for sex, smoking, pack-years, childhood and adulthood socioeconomic status, and all pesticides as coexposure.

No interaction was observed with exposure to all pesticides, herbicides and insecticides (results not shown).

AO, airflow obstruction; GOLD, Global Obstructive Lung Disease; RR, relative risk; VGDF, vapour, gases, dust and fumes.

Both GOLD and LLN definitions of fixed AO in our study produced similar effect estimates with most of the exposures except all pesticides exposure, where we found a significant association using GOLD definition, but when we used the LLN definition the association with all pesticides did not quite reach statistical significance. The previous study on occupational exposure and COPD in Switzerland also found similar to our results, although they used pre-BD to define COPD. ${ }^{19}$ Post-BD is essential to define fixed $\mathrm{AO}$, but there is still debate over the best cut-off values to define fixed $\mathrm{AO}^{29}$ The GOLD definition of fixed ratio $\left(\mathrm{FEV}_{1} /\right.$ FVC <0.7) has been widely used for clinical application as well as large-scale population-based studies. ${ }^{30} 31$ More recently, statistical reference equation-based LLN definition also provide an opportunity to overcome age-related overestimation of the total effect by GOLD. ${ }^{31}$ We observed very little variation between the two definitions of fixed AO, with only one person being classified as having fixed AO by the GOLD and not the LLN definition. This person was on the borderline of being categorised as having fixed $\mathrm{AO}$ by the LLN definition. Other data from this individual (ie, heavy personal smoking history and occupational history with high likelihood of occupational exposure to herbicides and all pesticides) and the relatively small change in the estimates between the two definitions we would not regard this person as an extreme outlier or having undue influence and so he has not been removed from the analysis.

The availability of post-BD data was a major strength of our study. The availability of work history calendars for the participants' entire working life was also a major strength and enabled the calculation of ever exposure and cumulative EU-years. We have attempted to minimise any bias related to recalling of work exposures by using standardised lifetime work history calendars and then assigning exposure via the use of a Job Exposure Matrix to estimate cumulative EU-years across all jobs. Job Exposure Matrices are affected by non-differential misclassification of exposure, which occurs when there is heterogeneity of exposure in a given job or occupation. However, this generally results in misclassification towards the null, leading to an underestimation of the effect of the exposure on risk of the disease. Multiple comparisons were performed but the associations, particularly with all pesticides and herbicides exposure, were consistent across several outcomes, suggesting genuine associations rather than chance findings. However, our laboratory attendees, enriched for asthma and chronic bronchitis and had similar clinical profiles despite the lung function testing.
In conclusion, our study has shown that both ever and cumulative EU-years to pesticides are associated with fixed $\mathrm{AO}$ and respiratory symptoms. We have also shown this effect of pesticides is independent of asthma. For other occupational exposures to VDGF, we found an association with fixed AO only in those without current asthma. However, we did not find any significant association between fixed $\mathrm{AO}$, and chronic bronchitis with exposure to mineral dust, gases/fumes and VGDF. Future population-based studies need to use post-BD to define fixed $\mathrm{AO}$, which allows asthma to be adequately taken into account. Our study has shown even in a middle-aged group of people, a significant proportion of fixed $\mathrm{AO}$ is associated with occupational exposures. Our findings highlight the need to reduce workplace exposure to pesticides by improving adherence to use of recommended protective equipment, and workplace monitoring of exposure levels could be implemented. By enhanced monitoring and use of protective equipment, the burden of COPD caused by occupational exposures has the potential to be substantially reduced.

\section{Author affiliations}

${ }^{1}$ Allergy and Lung Health Unit, Centre for Epidemiology and Biostatistics, School of Population and Global Health, The University of Melbourne, Melbourne, Victoria, Australia

${ }^{2}$ Murdoch Childrens Research Institute, Melbourne, Victoria, Australia ${ }^{3}$ Department of Epidemiology and Preventive Medicine, School of Public Health and Preventive Medicine, Monash University, Melbourne, Victoria, Australia

${ }^{4}$ Graduate Entry Medical School, University of Limerick, Limerick, Ireland

${ }^{5}$ Department of Respiratory and Sleep Medicine, Austin Hospital, Melbourne, Victoria, Australia

${ }^{6}$ Department of Medicine, University of Queensland, Brisbane, Queensland, Australia ${ }^{7}$ School of Medicine, University of Tasmania, Hobart, Tasmania, Australia

${ }^{8}$ Cancer Epidemiology and Intelligence Division, Cancer Council Victoria, Melbourne,

Victoria, Australia

${ }^{9}$ Faculty of Medicine, University of New South Wales, Sydney, New South Wales, Australia

${ }^{10}$ Allergy Immunology and Respiratory Medicine, The Alfred Hospital, Melbourne, Victoria, Australia

${ }^{11}$ Gold Coast University Hospital, Southport, Queensland, Australia

${ }^{12}$ Bond University, Robina, Queensland, Australia

${ }^{13}$ Environmental Epidemiology Division, Institute for Risk Assessment Sciences, Utrecht University, Utrecht, The Netherlands

Acknowledgements We acknowledge the Tasmanian Longitudinal Health Study (TAHS) participants and previous investigators. We thank Professor Mark Jenkins, PhD, Centre Director, Centre for Epidemiology and Biostatistics, School of Population and Global Health, The University of Melbourne, Victoria, who is a TAHS investigator but not a coauthor of this manuscript, for his assistance with obtaining funds and 
data collection. Furthermore, we acknowledge all the respiratory scientists who collected data in the lung function laboratories of Tasmania, Victoria, Queensland, and New South Wales; the research interviewers and data entry operators and the organisational roles of Ms Cathryn Wharton and Dr Desiree Mészáros.

Contributors Study concept and design: SMA, SCD, GB, RV, HK, EHW, MJA, MCM. Acquisition of data: SMA, SCD, JLP, PST, RWB, BRT, IHF, RV, HK, EHW, MJA, MCM.Analysis and interpretation of data: SMA, SCD, GB, MD, LCG, RV, HK, MJA, MCM. Drafting of the manuscript: SMA, SCD, GB, MD, MCM. Critical revision of the manuscript for important intellectual content: All Authors. Statistical analysis: SMA, LCG, MCM. Obtained funding: SCD, GB, DPJ, LCG, PST, JLH, RWB, BRT, IHF, EHW, MJA, MCM. Study supervision: SMA, SCD, GB, MD, MCM. SMA and MCM had full access to all the data in the study and take responsibility for the integrity of the data and the accuracy of the data analysis.

Funding Supported by the National Health and Medical Research Council of Australia; Clifford Craig Medical Research Trust of Tasmania; Victorian, Queensland, and Tasmanian Asthma Foundations; and the Australian Lung Foundation. SCD is supported by the NHMRC.

Competing interests None declared.

Patient consent Obtained.

Provenance and peer review Not commissioned; externally peer reviewed.

(c) Article author(s) (or their employer(s) unless otherwise stated in the text of the article) 2017. All rights reserved. No commercial use is permitted unless otherwise expressly granted.

\section{REFERENCES}

1 Celli BR, Decramer M, Wedzicha JA, et al. An official American Thoracic Society/ European Respiratory Society statement: research questions in COPD. Eur Respir J 2015;45:879-905.

2 Balmes J, Becklake M, Blanc P, et al. American Thoracic Society Statement: occupational contribution to the burden of airway disease. Am J Respir Crit Care Med 2003:167:787-97.

3 Eisner MD, Anthonisen N, Coultas D, et al. An official American Thoracic Society public policy statement: Novel risk factors and the global burden of chronic obstructive pulmonary disease. Am J Respir Crit Care Med 2010;182:693-718.

4 Alif SM, Dharmage SC, Bowatte G, et al. Occupational exposure and risk of chronic obstructive pulmonary disease: a systematic review and meta-analysis. Expert Rev Respir Med 2016;10:861-72.

5 Hansell A, Ghosh RE, Poole S, et al. Occupational risk factors for chronic respiratory disease in a New Zealand population using lifetime occupational history. J Occup Environ Med 2014:56:270-80.

6 Sterk PJ. Let's not forget: the GOLD criteria for COPD are based on postbronchodilator FEV1. Eur Respir J 2004;23:497-8.

7 Matheson MC, Benke G, Raven J, et al. Biological dust exposure in the workplace is a risk factor for chronic obstructive pulmonary disease. Thorax 2005;60:645-51.

8 Würtz ET, Schlünssen V, Malling TH, et al. Occupational chronic obstructive pulmonary disease in a danish Population-Based study. COPD 2015:12:435-43.

9 Lilley RC, Cryer PC, Firth HM, et al. Ascertainment of occupational histories in the working population: the occupational history calendar approach. Am J Ind Med 2011;54:21-31.

10 Mamane A, Baldi I, Tessier JF, et al. Occupational exposure to pesticides and respiratory health. Eur Respir Rev 2015:24:306-19.
11 Hernández AF, Parrón T, Alarcón R. Pesticides and asthma. Curr Opin Allergy Clin Immunol 2011;11:90-6.

12 de Jong K, Boezen HM, Kromhout $\mathrm{H}$, et al. Pesticides and other occupational exposures are associated with airway obstruction: the LifeLines cohort study. Occup Environ Med 2014;71:88-96.

13 de Jong K, Boezen HM, Kromhout H, et al. Association of occupational pesticide exposure with accelerated longitudinal decline in lung function. Am J Epidemiol 2014;179:1323-30.

14 Alif SM, Dharmage SC, Benke G, et al. Lifetime Occupational exposure to Vapor, gases/Fumes, dust and risk of COPD at 45 years: the Tasmanian Longitudinal Health Study (TAHS) (abstract). Am J Resp Crit Care Med 2016;193:A2989.

15 Matheson MC, Abramson MJ, Allen K, et al. TAHS investigator group. Cohort Profile: The Tasmanian Longitudinal Health STUDY (TAHS). Int J Epidemiol 2017:46:407-408i.

16 Miller MR, Hankinson J, Brusasco V, et al. Standardisation of spirometry. Eur Respir J 2005:26:319-38

17 Vestbo J, Hurd SS, Agustí AG, et al. Global strategy for the diagnosis, management, and prevention of chronic obstructive pulmonary disease: GOLD executive summary. Am J Respir Crit Care Med 2013;187:347-65.

18 Quanjer PH, Stanojevic S, Cole TJ, et al. Multi-ethnic reference values for spirometry for the 3-95-yr age range: the global lung function 2012 equations. Eur Respir J 2012;40:1324-43.

19 Mehta AJ, Miedinger D, Keidel D, et al. Occupational exposure to dusts, gases, and fumes and incidence of chronic obstructive pulmonary disease in the Swiss Cohort Study on Air Pollution and Lung and Heart Diseases in Adults. Am J Respir Crit Care Med 2012;185:1292-300

20 Hoppin JA, Valcin M, Henneberger PK, et al. Pesticide use and chronic bronchitis among farmers in the Agricultural Health Study. Am J Ind Med 2007;50:969-79.

21 Fieten $\mathrm{KB}$, Kromhout $\mathrm{H}$, Heederik $\mathrm{D}$, et al. Pesticide exposure and respiratory health of indigenous women in Costa Rica. Am J Epidemiol 2009;169:1500-6.

22 Faria NM, Facchini LA, Fassa AG, et al. Pesticides and respiratory symptoms among farmers. Rev Saude Publica 2005;39:973-81.

23 Sham'a FA, Skogstad M, Nijem K, et al. Cross-Shift changes in lung function among palestinian farmers during high- and Low-Exposure periods to Pesticides: a longitudinal study. Arch Environ Occup Health 2015;70:218-24.

24 Doust E, Ayres JG, Devereux G, et al. Is pesticide exposure a cause of obstructive airways disease? Eur Respir Rev 2014;23:180-92.

25 Peiris-John RJ, Ruberu DK, Wickremasinghe AR, et al. Low-level exposure to organophosphate pesticides leads to restrictive lung dysfunction. Respir Med 2005;99:1319-24.

26 Marchetti N, Garshick E, Kinney GL, et al. Association between occupational exposure and lung function, respiratory symptoms, and high-resolution computed tomography imaging in COPDGene. Am J Respir Crit Care Med 2014;190:756-62.

27 Lam KB, Yin P, Jiang CQ, et al. Past dust and GAS/FUME exposure and COPD in Chinese: the Guangzhou Biobank Cohort Study. Respir Med 2012;106:1421-8.

28 Sunyer J, Kogevinas M, Kromhout $\mathrm{H}$, et al. Pulmonary ventilatory defects and Occupational exposures in a Population-based study in Spain. Am J Respir Crit Care Med 1998;157:512-7.

29 Swanney MP, Ruppel G, Enright PL, et al. Using the lower limit of normal for the FEV1/FVC ratio reduces the misclassification of airway obstruction. Thorax 2008:63:1046-51.

30 Cerveri I, Corsico AG, Accordini S, et al. Underestimation of airflow obstruction among young adults using FEV1/FVC $<70 \%$ as a fixed cut-off: a longitudinal evaluation of clinical and functional outcomes. Thorax 2008;63:1040-5.

31 Roberts SD, Farber MO, Knox KS, et al. FEV1/FVC ratio of 70\% misclassifies patients with obstruction at the extremes of age. Chest 2006;130:200-6. 